\title{
Moisture or Humidity Problem
}

National Cancer Institute

\section{Source}

National Cancer Institute. Moisture or Humidity Problem. NCI Thesaurus. Code C62909.

Problem associated with an unsatisfactory humidity level in the storage or use environment which affects the device performance. 